\title{
Arterial Vimentin Is a Transglutaminase Substrate: A Link between Vasomotor Activity and Remodeling?
}

\author{
Madhu Gupta ${ }^{a}$ Charles S. Greenberg ${ }^{c}$ Delrae M. Eckman ${ }^{b}$ David C. Sane ${ }^{a}$ \\ Departments of a Internal Medicine/Cardiology and ${ }^{b}$ Pediatrics, Wake Forest University School of Medicine, \\ Winston-Salem, N.C., and ' Duke University Medical Center, Durham, N.C., USA
}

\section{Key Words}

Transglutaminase $\cdot$ Vimentin $\cdot$ Inward remodeling •

Cross-linking $\cdot$ Factor XIII

\begin{abstract}
Background/Aims: The transglutaminases (TG2 and factor XIIla) may contribute to the stability of arteries by cross-linking a variety of substrates, including extracellular matrix proteins and protease inhibitors. The preferred substrates have never been determined, however. Methods: We used an amine donor, 5-biotinamidopentylamine, that is covalently linked to acceptor glutamine residues, to determine transglutaminase substrates in carotid endarterectomy tissue. Results: The incorporation of 5-biotinamidopentylamine was calcium dependent, resulting in the labeling of several proteins that were detected by streptavidin-peroxidase and purified over a monomeric avidin affinity column. A major band of $42 \mathrm{kDa}$ that was eluted from the column was sequenced along with 2 additional bands ( 80 and $65 \mathrm{kDa}$ ), revealing an internal fragment of vimentin, transferrin and albumin, respectively. Vimentin dimers were detected in 5 out of 5 carotid plaque homogenates. Conclusions: Vimentin is a major arterial substrate for transglutaminases. It has previously been shown that TG2 activity and vimentin contribute to vasomotor activity of arteries. Furthermore, transglutaminases (both TG2 and factor XIIla), as well as vimentin, reg-
\end{abstract}

ulate structural alterations (inward remodeling) that occur in response to low flow states. Transglutaminase-mediated vimentin dimerization produces a novel unifying pathway by which vasodilatory and remodeling responses may be regulated.

Copyright $\odot 2007$ S. Karger AG, Basel

\section{Introduction}

The transglutaminases are a family of at least 9 homologous enzymes that catalyze the cross-linking of proteins by forming $\varepsilon(\gamma$-glutamyl)lysine isopeptide bonds, thereby providing stability to a variety of tissues against chemical, mechanical and proteolytic degradation [1]. Both the plasma transglutaminase (FXIIIa) and the tissue enzyme (TG2) have important roles in cardiovascular pathophysiology [2]. In the vasculature, arteriolar structure and function are regulated by the transglutaminases. Increased transglutaminase activity induces vasoconstriction and leads to inward remodeling, while inhibiting transglutaminase activity prevents remodeling and induces vasodilation [3-5].

Both TG2 and FXIIIa antigen are also present in larger arteries, especially in those with atherosclerotic plaque $[6,7]$. It has been proposed that transglutaminase activity contributes to plaque progression, but also

\section{KARGER \\ Fax +4161306 1234 \\ E-Mail karger@karger.ch}

www.karger.com
(C) 2007 S. Karger AG, Basel

$1018-1172 / 07 / 0445-0339 \$ 23.50 / 0$

Accessible online at:

www.karger.com/jvr
Dr. David C. Sane

Section of Cardiology, Wake Forest University School of Medicine

Medical Center Boulevard

Winston-Salem, NC 27157-1045 (USA)

Tel. +1 336716 7533, Fax +1 336716 6136, E-Mail dsane@wfubmc.edu 
promotes a beneficial effect by preventing plaque rupture [6]. A variety of known substrates for transglutaminase, including collagen types I and II [8], fibronectin [8], dermatan sulfate proteoglycan [9] and apolipoprotein (a) [10] are present in the extracellular matrix of the atherosclerotic plaque. However, the endogenous substrates that are responsible for the structural and functional effects of the transglutaminases in arteries and arterioles have not been elucidated. In this study, we demonstrate that vimentin is an endogenous transglutaminase substrate in carotid atherosclerotic plaque, and propose that the modification of vimentin by transglutaminases may regulate vascular structure and reactivity.

\section{Materials and Methods}

CHAPS, $\beta$-mercaptoethanol, dithiothreitol, extravidin-peroxidase conjugate, anti-vimentin and peroxidase-conjugated anti-goat IgG were all purchased from Sigma (St. Louis, Mo., USA). Amine donor substrate 5-biotinamidopentylamine, Supersignal chemiluminescent substrate, monomeric avidin kit and BCA protein quantification kit were obtained from Pierce (Rockford, Ill., USA). Reagents for electrophoresis and blotting were from Bio-Rad Laboratories (Hercules, Calif., USA). Carotid plaques were harvested by carotid endarterectomy at the North Carolina Baptist Hospital. The acquisition of tissue was approved by the Institutional Review Board of the Wake Forest University School of Medicine.

\section{Labeling of Carotid Artery Transglutaminase Substrates}

Carotid artery plaques were used to determine the major substrates for endogenous tissue transglutaminase within atherosclerotic arteries. The carotid endarterectomy plaque $(\sim 5 \mathrm{~g})$ was obtained immediately from the operating room, rinsed extensively in cold saline containing $10 \mathrm{mM}$ DTT to remove blood, then transported to the lab in ice-cold $100 \mathrm{mM}$ Tris, $\mathrm{pH} \mathrm{8.5,} \mathrm{containing} 10$ mM DTT. The tissue was then wrapped in aluminum foil, snap frozen in liquid nitrogen, pulverized with a hammer, then resuspended in lysis buffer (10 mM Tris- $\mathrm{HCl}$ pH $8.5 ; 1 \mathrm{mM}$ EGTA; $1 \mathrm{mM} \mathrm{MgCl} 2 ; 0.1 \mathrm{mM}$ AEBSF; $5 \mathrm{mM} \beta$-mercaptoethanol; $10 \%$ glycerol; 0.5\% CHAPS). The tissue was further homogenized using a Tissue Tearor (Biospec Inc.). Particulate matter was removed by centrifuging at $16,000 \mathrm{~g}$ for $20 \mathrm{~min}$ at $4^{\circ} \mathrm{C}$. The resultant supernatant $(2.5 \mathrm{ml})$ was separated into 2.0 - and 0.5 - $\mathrm{ml}$ aliquots. To the larger aliquot, $\mathrm{CaCl}_{2}$ (final concentration $10 \mathrm{mM}$ ), DTT (final concentration $20 \mathrm{mM}$ ) and 5-biotinamidopentylamine (final concentration $1 \mathrm{mM}$ ) were added. The $0.5-\mathrm{ml}$ aliquot was treated identically, except that $10 \mathrm{~mm}$ EDTA was added instead of $10 \mathrm{mM}$ $\mathrm{CaCl}_{2}$. The 2 aliquots were incubated for $2 \mathrm{~h}$ at $37^{\circ} \mathrm{C}$. In order to verify that transglutaminase-dependent biotinylation of plaque proteins had occurred, $20-\mu \mathrm{g}$ samples from each aliquot were loaded onto a $10 \%$ SDS-PAGE gel under reducing conditions, which was then transferred to nitrocellulose, blocked, incubated with streptavidin-peroxidase and developed with Supersignal chemiluminescent substrate.

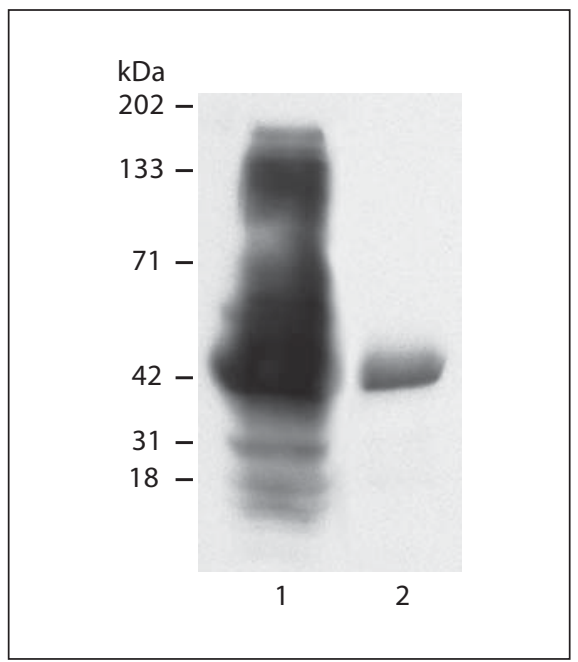

Fig. 1. Calcium-dependent biotinylation of plaque proteins by endogenous transglutaminase. Carotid endarterectomy plaque was prepared as described above. To $2.0 \mathrm{ml}$ of the homogenate, $\mathrm{CaCl}_{2}$ (final concentration $10 \mathrm{mM}$ ), DTT $(10 \mathrm{mM})$ and 5-biotinamidopentylamine $(1 \mathrm{mM})$ were added. To the other $0.5-\mathrm{ml}$ portion, the same ingredients were added, except that EDTA (10 mM) was substituted for $\mathrm{CaCl}_{2}$. Both samples were incubated for $2 \mathrm{~h}$ at $37^{\circ} \mathrm{C}$, then $20 \mu \mathrm{g}$ of total protein from each sample was separated under reducing conditions by $10 \%$ SDS-PAGE, blotted, blocked, incubated with streptavidin-peroxidase, then developed with chemiluminescence. Lane 1 is the incubation performed in the presence of $10 \mathrm{mM} \mathrm{CaCl}_{2}$. The blot shows that numerous proteins are labeled with 5-biotinamidopentylamine by a calcium-dependent endogenous transglutaminase. In the presence of $10 \mathrm{mM}$ EDTA (lane 2), only a single band is biotinylated. The origin of this single band is uncertain but may represent an endogenously biotinylated protein such as a carboxylase.

The larger aliquot, containing the biotinylated proteins, was dialyzed extensively against TBS, then PBS, to remove free 5-biotinamidopentylamine. The dialysate was then applied to a monomeric avidin affinity column that had been previously treated as recommended by the manufacturer to block all nonreversible binding sites. Unbound material was then removed by extensively washing the column with PBS (10 column volumes in $2.0-\mathrm{ml}$ fractions), with monitoring of the $\mathrm{OD}_{280}$ until it had reached baseline.

The bound, biotinylated proteins were eluted with $2.0-\mathrm{ml}$ fractions of $2 \mathrm{mM}$ D-biotin in PBS, until background absorbance was achieved. Fractions with $\mathrm{OD}_{280}$ greater than baseline were pooled, dialyzed against $\mathrm{H}_{2} \mathrm{O}$, then lyophilized. The lyophilized material was resuspended in $100 \mu \mathrm{l}$ of TBS and an equal volume of $2 \times$ SDS-PAGE sample buffer (containing $\beta$-mercaptoethanol) was added, the samples were boiled for $3 \mathrm{~min}$, then separated by $10 \%$ SDS-PAGE. The gel was electroblotted onto PVDF membrane and 3 major bands were excised and subjected to sequencing by automated Edman degradation. A small sample $(7 \mu \mathrm{l})$ was 


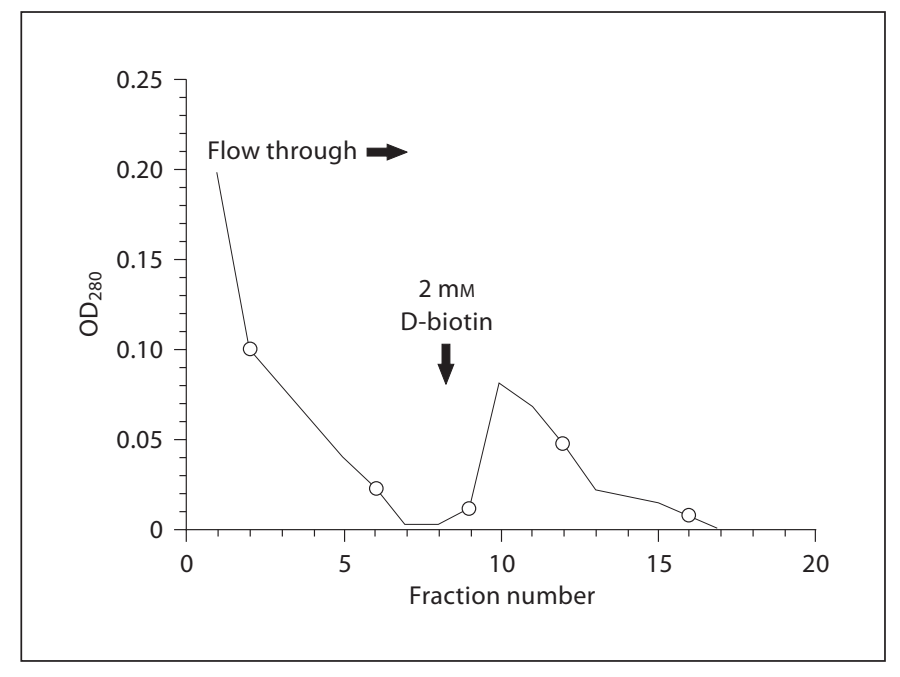

Fig. 2. Elution profile of biotinylated plaque proteins from monomeric avidin column. The biotinylated proteins from the calcium-containing reaction shown in figure 1 were applied to a monomeric avidin affinity column that had all irreversible biotinbinding sites blocked. Unbound material was washed off with PBS until the $\mathrm{OD}_{280}$ was at background, then bound material was eluted with $2.0-\mathrm{ml}$ fractions of $2 \mathrm{mM}$ D-biotin in PBS, again until background $\mathrm{OD}_{280}$ was attained. The eluted fractions were pooled, dialyzed against $\mathrm{H}_{2} \mathrm{O}$, lyophilized and further analyzed to confirm biotinylation and to sequence prominent bands.

also separated by SDS-PAGE, blotted, blocked, incubated with streptavidin-peroxidase and developed with chemiluminescence.

\section{$N$-Terminal Sequencing}

Amino acid sequence analyses were conducted in the Protein Analysis Core Laboratory of the Comprehensive Cancer Center of Wake Forest University. Samples were analyzed using a PE Biosystems model 492 protein sequencer. Amino acid sequences were searched against the SwissProt and PIR protein sequence databases using FASTA implemented by the Wisconsin Sequence Analysis Package provided by the Genetics Computer Group Inc. (Madison, Wisc., USA).

\section{Immunoblotting of Carotid Plaque Lysates for Vimentin}

Carotid endarterectomy tissue homogenates were prepared as described above. Protein concentrations of the extracts were determined using the BCA protein assay kit. Samples were resolved on $10 \%$ SDS-PAGE gels under reducing conditions and transferred to nitrocellulose. Blots were blocked in 5\% nonfat dry milk in TBST (20 mM Tris-HCl, pH 7.4, 137 mM NaCI, 0.1\% Tween 20) and incubated with anti-vimentin (Sigma V4630). The blots were washed and incubated with horseradish peroxidase-conjugated anti-goat IgG, then developed with Supersignal chemiluminescent substrate.

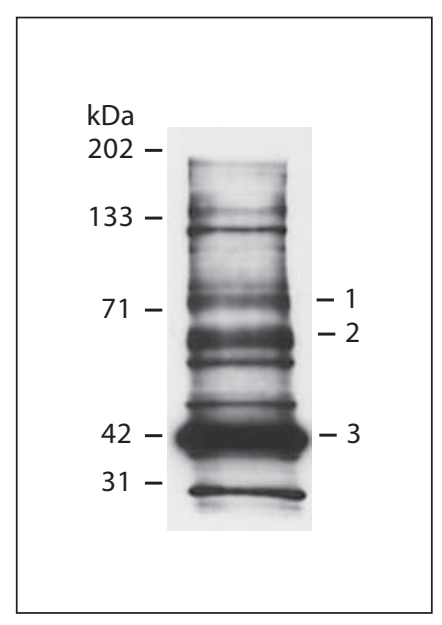

Fig. 3. Purified, biotinylated plaque proteins. The fractions eluted from the monomeric avidin column with $2 \mathrm{mM}$ D-biotin were pooled, dialyzed against $\mathrm{H}_{2} \mathrm{O}$, lyophilized, resuspended and separated in 2 lanes by $10 \%$ SDS-PAGE. The gel was transferred to a PVDF membrane. One lane was blocked, then incubated with streptavidin-peroxidase, then developed with ECL, and is shown to the right. The other lane (not shown) was stained with Coomassie blue, destained and prominent bands (labeled 1, 2 and 3 on the blot) were excised and sequenced. Protein 1 is transferrin, protein 2 is albumin and protein 3 is an internal fragment of vimentin.

\section{Results}

The biotinylation of plaque proteins by endogenous transglutaminase was calcium sensitive (fig. 1), consistent with the known calcium dependence of transglutaminase activity. The proteins that were biotinylated by endogenous plaque transglutaminase in the presence of $\mathrm{CaCl}_{2}$ (fig. 1, lane 1) were successfully eluted from the monomeric avidin affinity column (fig. 2). The eluted proteins were lyophilized and separated on a gel to demonstrate that the biotinylated transglutaminase substrates had been recovered (fig. 3). Proteins of approximately $140,120,90,80,65,60,50,42$, and $20 \mathrm{kDa}$ were purified and blotted to PVDF membrane (fig. 3). The major band of $42 \mathrm{kDa}$, along with 2 additional bands of 80 and 65 $\mathrm{kDa}$, was excised from the membrane and sequenced. In each case, the sequence obtained by automated Edman degradation is shown on top (in bold) and the known protein sequence obtained from the literature is diagrammed below (table 1).

The sequenced 11 residues of protein 1 closely match the $\mathrm{N}$-terminal sequence of transferrin [11]. The se- 
Table 1. Protein sequences

\begin{tabular}{|c|c|c|c|c|c|c|c|c|c|c|c|c|c|c|c|c|c|c|c|c|c|c|c|c|c|c|c|c|}
\hline \multicolumn{29}{|c|}{ Band 1: transferrin } \\
\hline V & $\mathbf{P}$ & D & $\mathbf{K}$ & $\mathbf{T}$ & V & $\mathbf{R}$ & $\mathbf{A}$ & $X$ & $A$ & V & & & & & & & & & & & & & & & & & & \\
\hline $\mathrm{V}^{1}$ & $\mathrm{P}$ & $\mathrm{D}$ & $\mathrm{K}$ & $\mathrm{T}$ & $\mathrm{V}$ & $\mathrm{R}$ & $\mathrm{W}$ & $\mathrm{C}$ & $\mathrm{A}$ & $\mathrm{V}$ & S & $\mathrm{E}$ & $\mathrm{H}$ & $\mathrm{E}$ & A & $\mathrm{T}$ & $\mathrm{K}$ & $\mathrm{C}$ & Q & $\mathrm{S}$ & $\mathrm{F}$ & $\mathrm{R}$ & $\ldots$ & & & & & \\
\hline \multicolumn{29}{|c|}{ Band 2: albumin } \\
\hline D & $\mathbf{A}$ & $\mathbf{H}$ & $\mathbf{K}$ & $\mathbf{S}$ & $\mathbf{E}$ & V & A & $\mathbf{H}$ & $\mathbf{R}$ & $\mathbf{F}$ & $\mathbf{K}$ & D & $\mathbf{L}$ & G & $\mathbf{E}$ & $\mathbf{E}$ & $\mathbf{N}$ & $\mathbf{F}$ & $\mathbf{K}$ & & & & & & & & & \\
\hline $\mathrm{D}^{1}$ & $\mathrm{~A}$ & $\mathrm{H}$ & $\mathrm{K}$ & $\mathrm{S}$ & $\mathrm{E}$ & $\mathrm{V}$ & $\mathrm{A}$ & $\mathrm{H}$ & $\mathrm{R}$ & $\mathrm{F}$ & $\mathrm{K}$ & $\mathrm{D}$ & $\mathrm{L}$ & G & $\mathrm{E}$ & $\mathrm{E}$ & $\mathrm{N}$ & $\mathrm{F}$ & $\mathrm{K}$ & A & $\mathrm{L}$ & $\mathrm{V}$ & $\mathrm{L}$ & I & $\mathrm{A}$ & $\mathrm{F}$ & A $\quad$ Q & $\mathrm{Y}$ \\
\hline \multicolumn{29}{|c|}{ Band 3: internal fragment of vimentin } \\
\hline & & & & & $S$ & $X$ & $\mathbf{V}$ & $\mathbf{P}$ & G & $\mathbf{V}$ & $\mathbf{R}$ & $\mathbf{L}$ & $\mathbf{L}$ & $\mathbf{E}$ & $\mathbf{D}$ & $\mathbf{S}$ & $\mathbf{V}$ & $\mathbf{D}$ & $\mathbf{F}$ & $\mathrm{S}$ & $\mathbf{L}$ & & & & & & & \\
\hline$\ldots \mathrm{A}$ & $\mathrm{V}$ & $\mathrm{R}$ & $\mathrm{L}$ & $\mathrm{R}$ & $\mathrm{S}^{72}$ & $\mathrm{~S}$ & $\mathrm{~V}$ & $\mathrm{P}$ & G & $\mathrm{V}$ & $\mathrm{R}$ & $\mathrm{L}$ & $\mathrm{L}$ & Q & $\mathrm{D}$ & $\mathrm{S}$ & $\mathrm{V}$ & $\mathrm{D}$ & $\mathrm{F}$ & $\mathrm{S}$ & & & & & & & & \\
\hline
\end{tabular}

Sequences obtained by automated Edman degradation are shown on top (in bold) and the published protein sequences are diagrammed below. The arrow indicates the site of cleavage of vimentin that produces the neoamino terminus revealed by sequencing protein 3.

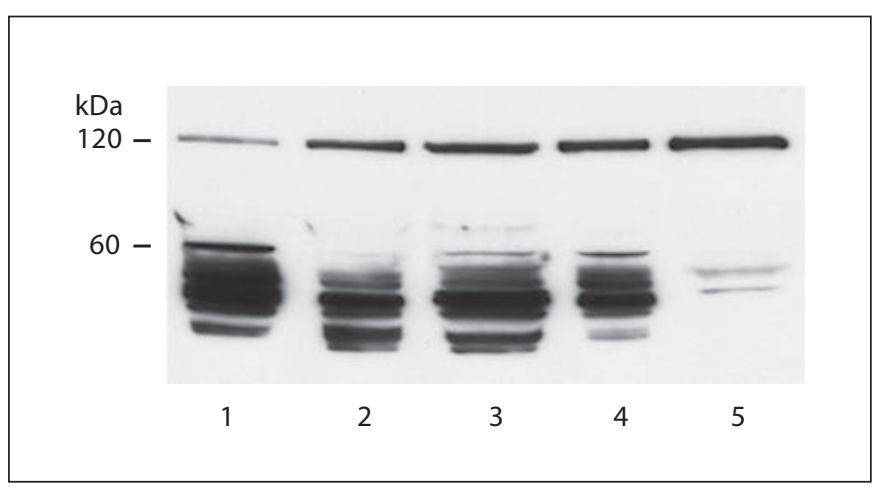

Fig. 4. Evidence for cross-linking of vimentin within carotid plaques. Homogenates of 5 human carotid endarterectomy plaques were prepared as described, then $20 \mu \mathrm{g}$ of protein separated under reducing conditions by $10 \%$ SDS-PAGE. Immunoblotting using anti-human vimentin resulted in the detection of vimentin monomer at $60 \mathrm{kDa}$ and an even more prominent apparent dimer band at $120 \mathrm{kDa}$ (proteolytic fragments were also observed). In some samples (lanes 2 and 5), there was very little monomer with predominance of dimer.

quenced 20 residues of protein 2 matched exactly with the N-terminus of human albumin [12].

Protein 3 at $\sim 42 \mathrm{kDa}$ represents an internal fragment of the intermediate filament protein vimentin. As shown in table 1, 20 cycles of protein 3 were sequenced with the results shown in bold with the reported sequences presented below [13]. There is a nearly identical match starting at serine residue 72 .

We examined carotid endarterectomy plaque tissue to determine whether vimentin could be detected in high- molecular-weight forms. Under reducing conditions, a $120-\mathrm{kDa}$ band was detected with anti-vimentin in all 5 samples, as well as the $60-\mathrm{kDa}$ monomer and apparent proteolytic fragments (fig. 4). In one sample (fig. 4, lane 5), the apparent vimentin dimer was the predominant antigen.

\section{Discussion}

In this paper, we have used 5-biotinamidopentylamine to identify several substrates of endogenous carotid artery atherosclerotic plaque tissue transglutaminase. Although many potential substrates have been identified [8-10], primarily by using purified extracellular matrix proteins, this study represents the first attempt to label substrates in homogenates of human atherosclerotic plaque. A similar strategy has been successfully employed to identify novel substrates of transglutaminase in the liver [14] and in HT29 colon carcinoma cells [15].

The major endogenous substrate was an internal fragment of vimentin. The intact protein was also a substrate, since dimers of $120 \mathrm{kDa}$, consistent with 2 full-length vimentin molecules, were found in arterial lysates. Vimentin is a class III intermediate filament protein primarily expressed in cells of mesenchymal origin, including endothelial cells and smooth muscle cells [16]. Purified vimentin and vimentin within the lens have previously been described as TG2 substrates [17-19], with the formation of cross-linked dimers being proposed to play a role in the development of cataracts [17-19]. Human lens epithelial cells exposed to oxidative stress form vimentin dimers in 
situ [19]. To our knowledge, our study is the first to show that vimentin is a substrate for transglutaminase in the vessel wall and to demonstrate the presence of crosslinked vimentin dimers in arterial tissue. The cross-linking of vimentin could be facilitated by the intracellular co-localization of transglutaminase and vimentin, as demonstrated in keratinocytes [18] and fibroblasts [20]. TG2 and FXIIIa are also present as extracellular transglutaminases [1]. It is possible that vimentin becomes a transglutaminase substrate when it is released during cellular apoptosis, an event that occurs with a relatively high frequency within the plaque $[21,22]$. It is notable in this regard that tissue transglutaminase activity is increased during apoptosis [23, 24]. Evidence for the cellular release of vimentin within the vessel wall has been demonstrated in patients with accelerated transplant vasculopathy. These patients have high levels of anti-endothelial cell antibodies, which are directed at a $56-$ to $58-\mathrm{kDa}$ antigen [25], which has been identified as vimentin [26].

We also demonstrated that albumin and transferrin were endogenous transglutaminase substrates. Thung et al. [27] previously reported that transglutaminase could cross-link human serum albumin into multimers (up to hexamers). Transglutaminase is also known to cross-link certain amine-containing drugs (such as isoniazid and hydralazine) to albumin [28]. To our knowledge, transferrin has not previously been described as a transglutaminase substrate. Using purified protein, we have confirmed that transferrin is a substrate for TG2 and FXIIIa (data not shown). However, the significance of albumin and transferrin serving as substrates for transglutaminases is currently unknown.
An important role for vimentin has been demonstrated in arterial physiology. Mice lacking vimentin have impaired arterial vasodilation in response to alterations in blood flow as a result of an imbalance in the levels of endothelin-1 and nitric oxide [29-31]. These effects may occur because of the critical role that cytoskeletal components play in mediating shear stress-induced release of endothelial-derived vasoactive substances. The absence of vimentin also has important consequences on vascular structure. Vimentin -/- mice have a reduction in inward remodeling in response to reduce blood flow in the carotid, but exhibit increased remodeling in response to elevated blood flow [31]. Inward remodeling, a structural reorganization of a constant amount of vascular tissue with a reduction in luminal diameter, occurs in settings of persistent vasoconstriction or a reduction in shear stress from reduced blood flow [32]. Both TG2 and FXIIIa have been shown to enhance inward remodeling in response to low flow states [3-5]. Furthermore, TG2 activity is associated with vasoconstrictive responses, perhaps mediated via the activation of the RhoA/ROCK-2 kinase pathway in vascular smooth muscle cells [33]. Since small GTPases including RhoA regulate vimentin and other cytomatrix components [34], we postulate that TG2-induced alterations of vimentin structure either directly (via cross-linking) or indirectly (via RhoA) regulate vasomotor tone. Furthermore, since both TG2 and vimentin also contribute to inward remodeling, we speculate that transglutaminase-mediated vimentin dimerization could provide a novel unifying pathway by which vasodilatory and remodeling responses are regulated.

\section{References}

1 Greenberg CS, Birckbichler PJ, Rice RH: Transglutaminases: multifunctional crosslinking enzymes that stabilize tissues. FASEB J 1991;5:3071-3077.

$\checkmark 2$ Sane DC, Kontos JL, Greenberg CS: Roles of transglutaminases in cardiac and vascular diseases. Front Biosci 2007;12:2530-2545.

$\checkmark 3$ Langille BL, Dajnowiec D: Cross-linking vasomotor tone and vascular remodeling: a novel function for tissue transglutaminase? Circ Res 2005;96:9-11.

-4 Bakker EN, Buus CL, Spaan JA, Perree J, Ganga A, Rolf TM, Sorop O, Bramsen LH, Mulvany MJ, VanBavel E: Small artery remodeling depends on tissue-type transglutaminase. Circ Res 2005;96:119-126.
Bakker EN, Pistea A, Spaan JAE, Rolf T, de Vries CJ, van Rooijen N, Candi E, VanBavel E: Flow-dependent remodeling of small arteries in mice deficient for tissue-type transglutaminase. Circ Res 2006;99:86-92.

6 Haroon ZA, Wannenburg T, Gupta M, Greenberg CS, Wallin R, Sane DC: Localization of tissue transglutaminase in human carotid and coronary artery atherosclerosis: implications for plaque stability and progression. Lab Invest 2001;81:83-93.

-7 Sumi Y, Inoue N, Azumi H, Seno T, Okuda M, Hirata K, Kawashima S, Hayashi Y, Itoh H, Yokoyama M: Expression of tissue transglutaminase and elafin in human coronary artery: implication for plaque instability. Atherosclerosis 2002;160:31-39.
8 Mosher DF: Cross-linking of fibronectin to collagenous proteins. Mol Cell Biochem 1984;58:63-68.

9 Kinsella MG, Wight TN: Formation of high molecular weight dermatan sulfate proteoglycan in bovine aortic endothelial cell cultures: evidence for transglutaminase-catalyzed cross-linking to fibronectin. J Biol Chem 1990;265:17891-17898.

10 Borth W, Chang V, Bishop P, Harpel PC: Lipoprotein (a) is a substrate for factor XIIIa and tissue transglutaminase. J Biol Chem 1991;266:18149-18153.

11 MacGillivray RT, Mendez E, Sinha SK, Sutton MR, Lineback-Zins J, Brew K: The complete amino acid sequence of human serum transferrin. Proc Natl Acad Sci USA 1982;79: 2504-2508. 
12 Meloun B, Moravek L, Kostka V: Complete amino acid sequence of human serum albumin. FEBS Lett 1975;58:134-137.

$\checkmark 13$ Honoré B, Madsen P, Basse B, Andersen A, Walbum E, Celis JE, Leffers H: Nucleotide sequence of cDNA covering the complete coding part of the human vimentin gene. Nucleic Acids Res 1990;18:6692.

-14 Ikura K, Kita K, Fujita I, Hashimoto H, Kawabata N: Identification of amine acceptor protein substrates of transglutaminase in liver extracts: use of 5-(biotinamido)-pentylamine as a probe. Arch Biochem Biophys 1998;356:280-286.

$>15$ Lee KN, Maxwell MD, Patterson MK Jr, Birckbichler PJ, Conway E: Identification of transglutaminase substrates in HT29 colon cancer cells: use of 5-(biotinamido)-pentylamine as a transglutaminase-specific probe. Biochim Biophys Acta 1992;1136:12-16.

$\checkmark 16$ Fuchs E, Weber K: Intermediate filaments: structure, dynamics, function and disease. Ann Rev Biochem 1994;63:345-382.

-17 Clément S, Velasco PT, Murthy SNP, Wilson JH, Lukas TJ, Goldman RD, Lorand L: The intermediate filament protein, vimentin, in the lens is a target for cross-linking by transglutaminase. J Biol Chem 1998;273:76047609.

- 18 Candi E, Oddi S, Terrinoni A, Paradisi A, Ranalli M, Finazzi-Agro A, Melino G: Transglutaminase cross-links loricrin, involucrin and small proline-rich proteins in vitro. J Biol Chem 2001;276:35014-35023.

$\checkmark 19$ Shin DM, Jeon JH, Kim CW, Cho SY, Kwon JC, Lee HJ, Choi KH, Park SC, Kim IG: Cell type-specific activation of intracellular transglutaminase 2 by oxidative stress or ultraviolet irradiation: implications of transglutaminase 2 in age-related cataractogenesis. J Biol Chem 2004;279:15032-15039.
20 Trejo-Skalli AV, Velasco PT, Murthy SN, Lorand L, Goldman RD: Association of a transglutaminase-related antigen with intermediate filaments. Proc Natl Acad Sci USA 1995: 92:8940-8944

21 Bennett MR, Macdonald K, Chan S-W, Boyle JJ, Weissberg PL: Cooperative interactions between $\mathrm{RB}$ and p53 regulate cell proliferation, cell senescence and apoptosis in human VSMC from atherosclerotic plaques. Circ Res 1998;82:704-712.

22 Bennett MR, Evan GI, Schwartz SM: Apoptosis of human vascular smooth muscle cells derived from atherosclerotic plaque to $\mathrm{p} 53$ mediated apoptosis. Circ Res 1997;81:591599.

23 Fesus L: Transglutaminase-catalyzed protein cross-linking in the molecular program of apoptosis and its relationship to neuronal processes. Cell Mol Neurobiol 1998;18:683694.

24 Verderio E, Nicholas B, Gross S, Griffin M: Regulated expression of tissue transglutaminase in Swiss 3T3 fibroblasts: effects on the processing of fibronectin, cell attachment and cell death. Exp Cell Res 1998;239: 119-138.

25 Dunn MJ, Crisp SJ, Rose ML, Taylor PM, Yacoub MH: Anti-endothelial antibodies and coronary artery disease after cardiac transplantation. Lancet 1992;339:1566-1570.

26 Atinou A, Collins A: Molecular cloning and expression of 56-58 KD antigen associated with transplant coronary artery disease. Biochem Biophys Res Commun 1997;2336:716718.

27 Thung SN, Wang D-F, Fasy TM, Hood A, Gerber MA: Hepatitis B surface antigen binds to human serum albumin cross-linked by transglutaminase. Hepatology 1989;9: 726-730.
28 Buxman MM: The role of enzymatic coupling of drugs to proteins in induction of drug specific antibodies. J Invest Dermatol 1979;73:250-255.

29 Terzi F, Henrion D, Colucci-Guyon E, Federici $\mathrm{P}$, Babinet $\mathrm{C}$, Levy $\mathrm{BI}$, Braind $\mathrm{P}$, Friedlander G: Reduction of renal mass is lethal in mice lacking vimentin. J Clin Invest 1997; 100:1520-1528.

30 Henrion D, Terzi F, Matrougui K, Duriez M, Boulanger CM, Colucci-Guyon E, Babinet C, Braind P, Friedlander G, Poitevin P, Levy B: Impaired flow-induced dilation in mesenteric resistance arteries from mice lacking vimentin. J Clin Invest 1997;100:29092914.

31 Schiffers PM, Henrion D, Boulanger CM, Colucci-Guyon E, Langa-Vuves F, vanEssen H, Fazzi GE, Levy BI, De Mey JG: Altered flow-induced arterial remodeling in vimentin-deficient mice. Arterioscler Thromb Vasc Biol 2000;20:611-616.

32 Mulvany MJ, Baumbach GL, Aalkjaer C, Heagerty AM, Korsgaard N, Schiffrin EL, Heistad DD: Vascular remodeling. Hypertension 1996;28:505-506.

-33 Janiak A, Zemskov EA, Belkin AM: Cell surface transglutaminase promotes RhoA activation via integrin clustering and suppression of the Src-p190TRhoGAP signaling pathway. Mol Biol Cell 2006;17:1606-1619.

34 Meriane M, Mary S, Comunale F, Vignal E, Fort P, Gauthier-Rouviere C: Cdc42Hs and Racl GTPases induce the collapse of the vimentin intermediate filament network. J Biol Chem 2000;275:33046-33052. 